\title{
A study on influencing factors of channel alliance relationship of Chinese corporations
}

\author{
(C) Higher Education Press and Springer-Verlag 2009
}

\begin{abstract}
Channel alliance is regarded as the most advanced form of channel relationships. The extant literature mainly focuses on commitment, trust, communication and cooperation as influencing factors of channel alliance relationship. This paper empirically explores influencing factors of channel alliance relationship in Chinese enterprises, and their respective degrees of influence, particularly those of personal relationship and government administrative factors. Research hypotheses were tasted based on a survey of automobile vendors and dealers. Three most important influencing factors were identified "commitment and trust", "communication and cooperation", and "returns".
\end{abstract}

Keywords channel alliance relationship, commitment and trust, communication and cooperation, personal relationship, administrative factor

摘要 渠道联盟被认为是渠道关系中最好的形式。学术界对渠道联盟关系影响因素 的研究主要集中在承诺、信任、沟通与合作等方面。本文实证研究了影响中国企业 渠道联盟关系的若干因素及其影响程度, 特别是探讨了私人关系和行政因素等的影 响程度。

关键词 渠道联盟关系, 承诺与信任, 沟通与合作, 私人关系, 行政因素

Translated from Nankai Guanli Pinglun 南开管理评论 (Nankai Business Review), 2006, 6(1): $42-48$

CHEN Tao $(\bowtie)$

School of Management, Wuhan University of Science and Technology, Wuhan 430081, China

E-mail: ct3773@126.com

PAN Zhe

School of Management, Wuhan University of Science and Technology, Wuhan 430081, China

E-mail: tczjw@163.com 


\section{Research background}

Since the 1990s, in the Western marketing channel research area, attention has been shifted to channel relationship and alliance. Among all channel relationships, channel alliance has been regarded the most advanced form. In an alliance, two or more organizations are linked by means of law, economy or interpersonal relationship, and operate for the common benefits of all parties. The development of this kind of relationship is influenced by many factors. Generally speaking, studies on influencing factors of channel alliance relationship could be classified in to the following four categories.

\subsection{Communication, trust, commitment and channel alliance}

Commitment lies in the core of the relationship network of enterprises and their various partners (suppliers, clients and inner employees, etc.) (Morgan and Hunt, 1994). Stern (2001) argued that the essence of channel alliance is commitment and trust and both upstream and downstream enterprises will strive to establish and promote channel alliance relationship in order to sustain their competition advantages and to achieve express profits (Stern, 2001).

Manufacturers can benefit by fostering good communication with distributors (Anderson and Narus, 1990). The general procedures of communication in a channel alliance are: commitment, fulfill the commitment, fulfill the commitment to whom does the same to you. If one party carries out the commitment, the other party should invest with no hesitation, and these relationship-specific investment and communication can create trust (Mohr and Nevin, 1990).

\subsection{Mutual behavior, satisfaction and channel alliance}

To a certain degree, alliance is the function of daily mutual behaviors. Daily mutual behaviors include economic performance and non-economic satisfaction. The former is both the reason and result of trustful relationship, while the latter mainly exists in an interpersonal context. Satisfied channel member feel comfortable and relaxed when working together with the other party and consider the partner respectable (Mohr and Nevin 1990). Personal relationship is usually the tie of establishing and maintaining the most reliable alliance relationship. The good or bad personal relationship among managers on both parties is one of the reasons which determine whether the alliance is efficient or not (Landry, 1998).

High satisfaction among channel members will promote the inner efficiency while low satisfaction will reduce the efficiency (Robicheaux and El-Ansary, 1975). 
Mutual satisfaction among channel members will reduce channel friction, moderate dysfunctional channel conflict, and enhance channel efficiency (Lusch, 1976).

\subsection{Continuity and channel alliance}

Channel alliance is based on continuity as the channel members' wish, because the downstream members fear that the upstream members will capture their business or they have to renegotiate them, while the upstream members also fear for losing the downstream market. Presuming expectancy of continuity exists, the next step to establish an alliance is to gain loyalty of the other party. Both parties' specific investment to relationship will produce an extraordinary effect. As time goes by, the maintaining and adding value to investment accumulation itself becomes an objective of maintaining the alliance (Heide, 1992).

\subsection{Partnership, environment and channel alliance}

Cooperation is bi-directional communication. Therefore, channel members must pay attention to cooperation with other members when considering establishing a channel alliance relationship (Brouthers, 1995).

In the context of alliance, the level of trust is related to decision structure. Power centralization does harm to trust and destroys participatory whereas cooperative and daily mutual behaviors promote trust; decision formalization also does harm to trust. On the contrary, in a relatively relaxed environment, trust will be enhanced, which will encourage channel members to work together and provide corresponding rewards to channel members (Liu, 2002). As a result, enterprises should select those complementary partners to establish alliance with (Stern, 2001).

In sum, foreign scholars have widely adopted behavior science and social science theory to study channel alliance relationship and its influencing factors. A majority of these studies were conducted from the perspective of channel relationship, or derived from other relevant research. For example, some studies on the influencing factors of channel strategic alliance originated from research of strategic alliance relationship. However, there has been limited research on the influencing factors of channel alliance relationship, especially in a transitional economy like China.

Relevant domestic research has mainly centered on mere description and summarization of the conceptions and features of channel strategic alliance relationship. There has been little theoretical and empirical research inton the influencing factors of channel alliance relationship. Among domestic researchs, Zhao and Dong (2001) studied the manufacturer-seller alliance from a manufacturer's perspective. They argued that manufacturer-seller alliance is a 
new feasible mechanism for coordinating incompatibilities among the present situation of channels and requirement for channel efficiency and cost advantage. Yang (2003) explored a series of difficult problems involved in the establishment and maintenance of channel alliance, such as possible trust building and maintenance, avoid the restoration of channel power, and meditation of conflicts between producers and sellers. He and Zhou (2004) reviewed existing literature on the antecedent factors and result variables of mutual trust in a channel strategic alliance and proposed a theoretical model of mutual trust and relevant propositions. Chen et al. (2005) studied the motivations behind channel alliance formation from the perspectives of suppliers, dealers, upstream/downstream members of suppliers/dealers and their interrelationship.

Based on the above research, we conclude that on the one hand, studying the influencing factors of channel alliance relationship can fill a gap in relevant domestic research, thus laying a preliminary foundation for future research in the field. On the other hand, this study can provide important implications for both upstream and downstream members in a channel alliance on how to establish and maintain good channel relationship.

\section{Hypothesis development and model building}

\subsection{Influencing factors of channel alliance and relevant hypothesis}

\subsubsection{Commitment/Relationship commitment}

Commitment lies in the core of a company's relationships with its partners (e.g., suppliers, customers, inner employees). Relationship commitment implies a desire and confidence to build a stable relationship and willingness to give up short-term interest in exchange of long-standing relationship (Anderson and Weitz, 1992). Commitment is usually conceptualized as a guarantee of certain or uncertain relationships between transaction partners from the perspective of commitment behavior because it is more suitable for quantitative analysis (Dwyer, 1994).

As the old saying goes, "promise worth a thousand pieces of gold", which well embodies the traditional business ethics in Chinese culture. High level of commitment not only promotes a constant, long-term channel alliance relationship, but also becomes an indispensable link when building up channel alliance. Therefore, Chinese enterprises will highlight the influence of commitment on mutual relationship if they want to build a stable and long-term alliance 
relationship with their partners. Accordingly, the following research hypothesis is proposed:

H1 Channel members' evaluation on their partner's commitment is positively related to the channel alliance relationship.

\subsubsection{Trust}

Trust underlies all alliance relationships, which means that one side of a transaction believes that the behaviors of the other side will facilitate rather than hinder their mutual relationship. As an influence factor of channel alliance relationship, trust lays a main foundation for the social-political relationship between manufacturers and distributors.

Trust plays an important role in maintaining the relationship with one's distributors. In order to maximize the long-term interests of the whole alliance, some alliance members may sometimes have to give up their own short-term interests. Under such circumstances, mutual trust helps the "sufferer" make some concessions whole-heartedly and sincerely. Empirical study has demonstrated that that manufacturers and distributors can obtain higher level of income from mutual trust relationship, and that manufacturers who maintain better relationship with distributors can gain more competitive advantages (Kumar, 1995). Trust helps reduce transaction costs. Stable relationship based on mutual trust could stabilize prices, obtain better returns, improve each side's ability to satisfy market needs, achieve economies of scale, and utilize marketing edge (Dixon and Wilkinson, 1986). When a certain type of mutual trust is established, information communication among alliance members becomes more reliable and efficient, and the degree of dependence on detailed contract and perfect supervision mechanism decreases greatly, thus it reduces transaction costs effectively and improves the operational efficiency of alliance relationship.

Confucian cultures contend the principles of faith and harmony, that is, faith exists between friends and communication breakdown occurs due to lack of faith. This cultural emphasizes credit, trust, justice and fulfillment is embodied as requirement of having faith in one's business partners. In Chinese traditional culture, faith is an important moral virtue while trust helps bring alliance and union into reality. In China, the establishment of effective enterprise credit system acts as a bulwark of mutual trust and long-term cooperation among different alliance members. A good alliance without mutual trust among its members is almost unimaginable. Therefore, members of enterprises in china should emphasize the influence of trust on mutual relationship if they want to build alliance relationship. Accordingly, the following research hypothesis is 
presented:

H2 Channel members' evaluation on their partner's trust is positively related to the channel alliance relationship.

\subsubsection{Cooperation}

Cooperation refers to both parties in a relationship work in close conjunction with one another to realize the full potential of this collaboration. Successful alliance relationships are often accompanied with cooperative behaviors in order to attain common target. In China, common cooperative behaviors in channel alliance involve coordinated promotion, inventory management, exclusive products, information sharing, training action and regional protection, etc. Under the circumstances of fierce market competition, cooperation and alliance among channel members symbolizes the gradual maturity of Chinese market. Therefore, when attempting to build a channel alliance relationship, an enterprise should cooperate closely with its business partners. We thus assume the following hypothesis:

H3 Channel members' evaluation on their partner's cooperation is positively related to the channel alliance relationship.

\subsubsection{Power balancing}

Power balancing means that manufacturers do not take advantage of their suppliers by means of big orders, but try to seek power balancing between both sides. In other words, neither party is highly dependent on the other.

Although traditional theories emphasize that the maintenance of enterprise's cooperation depends on relationship of mutual dependence on one another among members and asymmetric power (Anderson, 1990), theoretical study and practice both at home and abroad have shown that most of strategic alliances based on these traditional theories end in failure. There are two possible explanations.

Alliance members at a disadvantage may worry being taken advantage of by those in more advantageous positions. Thus, these "weak" enterprises wish to strengthen their position in the alliance to gain more negotiating power. Therefore, all alliance members make efforts to avoid becoming excessively dependent on others. Meanwhile, they also attempt to make themselves more indispensable to the alliance. Under such circumstances, there is no real cooperation except fighting for more advantageous position in the alliance $(\mathrm{Li}$, 1998). When well balanced in terms of power, however, suppliers will be more loyal to the channel alliance for there is no need to worry about being exploited. 
Likewise, when a purchaser is not excessively dependent on a certain supplier and there is no need to search for substitute suppliers or goods, it will remain loyal to the alliance relationship with the supplier (Coughlan et al, 2001). Therefore, enterprises in a channel relationship should emphasize close cooperation with other members if an alliance relationship is to be built:

H4 Evaluation of channel members on their partner's power balancing is positively related to the channel alliance relationship.

\subsubsection{Specific investment}

Specific investment refers to assets invested in support of certain a special transactions. The assets can not be arranged to other trading without sacrificing some productivity of the assets or increasing transaction costs of the new trading (David et al., 1999).

Specific investment is a double-edged sword. On the one hand, in doing so, an enterprise sends to its business partners a signal of its emphasis on and expectation of long-term and stable cooperation relationship. On the other hand, specific investment increases the so-called switching cost, leading to fundamental changes in mutual relationship (Williamson, 1985). Therefore, we tend to regard specific investment as the outcome of commitment and trust, a signal of commitment to constant cooperation relationship. Specific investment helps to improve other alliance members' trust and commitment level in the establishment of channel alliance relationship, improving indirectly the built-up of channel alliance relationship. On the other hand, the entity, specificity, and irreversibility features of specific investment may also exert direct impacts on the establishment of channel alliance relationship. We thus develop the next hypothesis as follows:

H5 Evaluation of channel members on their partner's specific investment is positively related to the channel alliance relationship.

\subsubsection{Opportunism}

Opportunism refers to the adoption of deceitful behaviors in maximization of one's self-interest. It also referred to as a kind of egoism in pursuit of profit. Opportunism manifests as camouflage and swindle in the initial stage of relationship establishment and as all kinds of sabotaging behaviors in the stage of relationship maintenance, making the observed behaviors inconsistent with what have been regulated in the original contract and agreement. Obviously, opportunistic behaviors do harm to the level of mutual trust among channel 
relation members, which in turn lead to a lowered level of commitment. We hence need to minimize the impact of opportunism in an alliance. Due to the unevenness and uncertainty of Chinese market, opportunism has become the most frequently occurred moral risks in enterprises' channel relationships (Bai and Wang, 2006). For those channel members who choose to build a long-term and stable strategic alliance relationship, they are less likely to get involved in opportunistic behaviors. Therefore, we hypothesize that:

H6 Evaluation of channel members on their partner's opportunism behavior tendency is negatively related to the channel alliance relationship.

\subsubsection{Special benefits}

Special benefits refer to some type of unique benefits you obtain from trading with a particular business partner, which cannot be obtained elsewhere from other partners. Because special benefits are inextricably linked with a particular partner and changing of business partners usually accompanies with loss of the special benefits. Therefore, the existence of special benefits not only increases switching cost and limits the possibility of opportunistic behaviors, but also helps to improve level of commitment, which is important to the establishment and maintenance of channel alliance relationship. Drawing on the above rationale, we propose the following hypothesis:

H7 The evaluation of channel members have on the special benefits they receive from trading with particular business partners is positively related to the channel alliance relationship.

\subsubsection{Personal ties (Relationship)}

In China, the influence of interpersonal relationships and interpersonal trust (usually referred to as Guanxi in Chinese) on organizational behaviors is significant. Relationship is an indispensable part of Chinese social organizations, and personal ties play vital roles in the daily life of Chinese people, including business field. In Western countries, relationship comes from business, but it is just the opposite in China. Good relationship is a must when doing business in China (Vanhonacker, 2004).

Personal ties lay good foundation for establishing and maintaining highly reliable alliance relationship. Good relationship among managers of different enterprises is important to the overall efficiency of an alliance. Especially in Chinese business culture and business activities, personal ties is usually regarded as a key variable (Han and Xi, 2001), which functions significantly in 
building mutual confidence, constructing reciprocal network, and achieving long-term profits, reducing business friction and strengthening good-intentioned interaction (Zhuang and $\mathrm{Xi}, 2004$ ). Relevant study has suggested that a significant difference between Eastern and Western philosophies of business lies in that Chinese pay more attention to personal ties when doing business while their Western peers lay greater emphasis on contract abiding (Arias, 1998; Davies at el., 1995). Such a difference also embodies itself in business activities. For example, when choosing distributors, manufacturers may lower the threshold of channel relationship, if the top managers of both sides know each other before, or have certain personal ties, which imply, to a certain degree, that both parties may share a common enterprise culture or value. The impact of personal ties on channel alliance relationship can not be ignored in the context of Chinese culture:

Moreover, it is impossible to establish and maintain long-term strategic alliance relationship among enterprises with endless disputes. The influence of personal ties on alliance relationship is indirectly achieved by trust and good personal ties help to improve the level of trust, which is especially crucial in China where third-party arbitration is lacking and other restricting forces is comparatively weak. Good personal ties are advantageous for those outside a business circle to enter and become a member (Yang, 1995). We thus assume that:

H8 Evaluation of channel members on their personal ties with other members is positively related to the channel alliance relationship.

\subsubsection{Communication}

Communication here means to share valuable and timely information formally or informally among companies. It has been widely accepted that valid communication plays an important role in society and business relationship. Communication is the fountainhead of alliance relationship. Communication in a good relationship includes three aspects: setting up goals and making market plans together, the quality of communication and the degree of information sharing. Good communication in all the above three aspects improve the level of commitment and trust among different participants. If enterprises want to build channel alliance relationship, they should set up good communication platforms, ensure the timeliness of information transmission, improve the sharing of information, solve the problem of asymmetric information among different channel members, and increase the level of trust. Accordingly, the following research hypothesis is presented:

H9 Evaluation of channel members on the communication among 
different member enterprises is relatively related to the channel alliance relationship.

\subsubsection{Government influence}

Government influence (including relevant administrative means and policies) is recognized as an important exterior factor in almost all analyses of enterprise's environment (Hutt at el., 1986; Grewal, Rajdeep and Ravi, 2002). Even in a market economy, technology and market changes are deeply embedded in a network of social relationships, especially the relationship with government. In China, the government influences enterprise behaviors by adopting a variety of indirect means, such as taxes exemption (e.g., newly published government policies aiming to strengthen supervision over vehicle distribution channels or to encourage establishment of $4 \mathrm{~S}$ shops). Whether government factors influence enterprises' channel alliance relationship remains to be explored. However, enterprises are affected in different aspects at different stages of market development in a transitional economy like China. Different institutionalized linkages, such as commercial organizations in state-owned enterprises, could promote enterprise to adopt different strategies to reduce business risks by different strategy, and different enterprises may face different market competition and pressure from government's normative authority (Zhou et al., 2003). Considering that government has always been influencing the operation of Chinese enterprises, the following research hypothesis is proposed:

H10 Government factors are significantly related to the channel alliance relationship.

\subsection{Model development}

Morgan and Hunt (1994) pointed out that channel structure characterized by trust and commitment can induce trust among channel members, which will enhance the performance of the whole channel system. They built a theoretic model-Key Medium Variable Model (KMV) with trust and commitment as the key medium variables. In this paper, we try to explore the impact of different factors on channel alliance. Based on the KMV model and other relevant literature, we construct a preliminary hypothesis model of the influencing factors of Chinese enterprises channel alliance relationship (Fig. 1) as follows: 


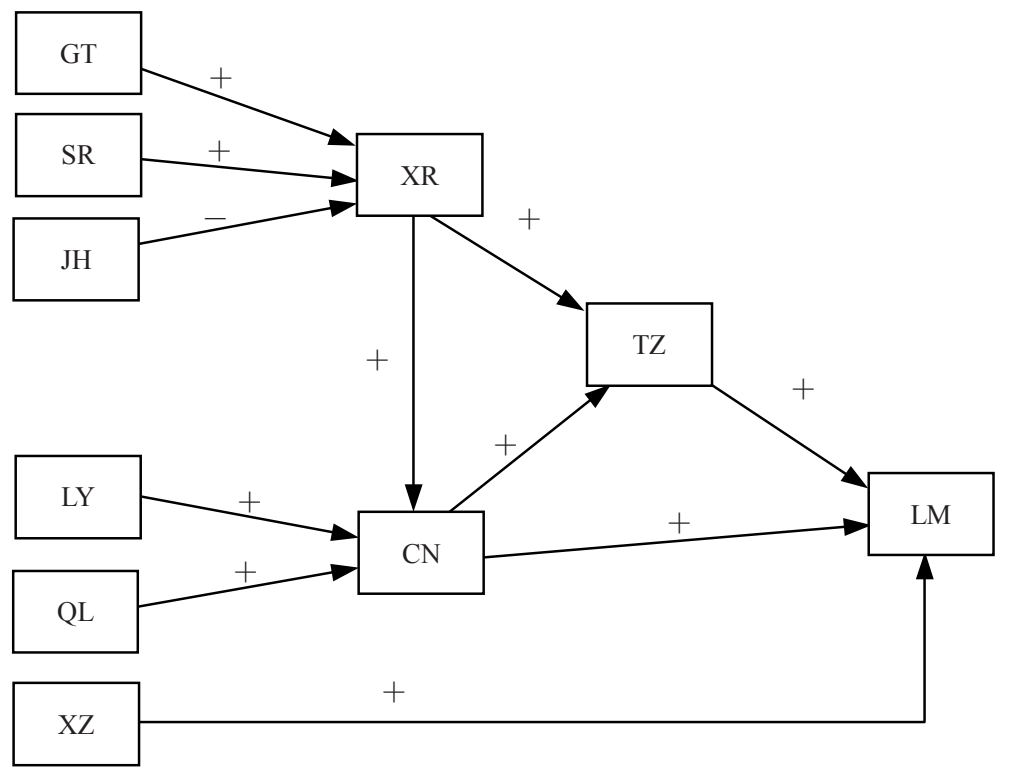

Fig. 1 Model of the influencing factors of channel alliance relationship

Note: 1.+: Positively related; - : negatively related.

2. GT: Communication; SR: Personal relationship; JH: Opportunism; LY: Extra returns.

3. QL: Power balance; XZ: Government factors; XR: Trust; TZ: Specific investment; $\mathrm{CN}$ : Commitment; LM: Alliance.

\section{Research method}

\subsection{Questionnaire design}

Our research intends to identify the factors that influence channel alliance by studying alliance members' evaluation of the channel alliance relationship. Therefore, it is necessary to measure the attitude tendency of channel alliance relationship under different potential influencing factors. Likert scale was used in this research. The questionnaire contained three parts:

Part 1: Respondents were required to evaluate the levels of different influencing factors of alliance relationship.

Part 2: Respondents were asked to evaluate the degree of influence of each influencing factor on channel alliance relationship.

Part 3: Respondents were asked to report their enterprises' basic information (e.g., enterprise type, sales revenue, the number of employees). 


\subsection{Investigation and data collection}

\subsubsection{Investigation}

The respondents mainly came from two groups: major domestic automakers as suppliers (manufacturers), and full-service dealers (4S shops) in Wuhan city and Guangzhou city. There were two reasons for choosing the automobile industry as our target industry:

First, in recent years, China's auto sales market has witnessed significant changes. Many new sales modes have been introduced. In comparison with older sales modes, the newer ones have changed greatly in distribution channels and channel relationship, providing a golden chance for studying the development, evolution and influencing factors of channel relationship.

Second, the purpose of this paper is to identify the influencing factor of channel alliance. The relationship between $4 \mathrm{~S}$ shops and automakers is a typical manufacturer and dealer relationship, thus we can use it to explore the features and constituent elements of channel alliance relationship.

The relationship between a $4 \mathrm{~S}$ shop and an automobile manufacturer can be characterized as follows: First, close cooperation exists between an automobile manufacturer and its dealers. Although they are legally independent companies, mutual integration is realized in logistics and capital flow (automobile manufacturers are in charge of product distribution, while dealers pay in advance), as well as in information flow as dealers are involved in the inner network of manufacturers. Second, the common goal shared by $4 \mathrm{~S}$ shops and its automobile manufacturer stems from all-round and deep cooperation. Third, considerable mutual trust has evolved from long-term, information-sharing cooperation, which enables them to know each better and enhance their mutual understandings. Fourth, a long-lasting relationship is essential for both parties. The priority of $4 \mathrm{~S}$ shops and automobile manufacturers is no longer short-term interests, but the maximization of long-term mutual gains, and the enhancement and maintenance of the relationship. Therefore, studying the relationship between $4 \mathrm{~S}$ shops and automobile manufacturers is of significance and representative of studies on channel alliance relationships

\subsubsection{Data collection}

The sample of this survey consists of two parts: the supplier sample and dealer sample. The latter mainly includes domestic automobile dealers. Our data collection methods included on-site visits, telephone interviews, and emails. On-site visits were mainly through two ways: visiting 4S shops in Wuhan and Guangzhou where the business flourished, and visiting showcases of dealers in 
auto exhibitions. Moreover, supplier data were collected mainly through dealers' mailing to their suppliers, supplemented by direct emails from the researchers. In the above process, authorized dealers sent the questionnaires by email to their corresponding suppliers. To ensure the size of the sample was adequate, emails were sent directly by the researchers to the suppliers in the meanwhile.

Since this survey focused on channel alliance relationship in the automobile industry, people who filled in the questionnaires should be fully aware of the relationship between their company and its alliance partner. Therefore, corresponding persons in charge (head of the market department or vice manager) were chosen to fill in the questionnaires. In total, 200 questionnaires were sent out, including 90 paper questionnaires, 80 emails and 30 phone-calls. Lastly, 137 questionnaires were returned with a return rate of $68 \%$, which was quite satisfactory.

\subsubsection{Sample characteristics}

The second part of the questionnaire was designed to gather basic information of both the enterprise and the individual being surveyed, such as business type, the number of employees, scale of the enterprise, the position of the informant. In our survey, $53.5 \%$ of the informants were those who could claim responsibility for the reliability and accuracy of the investigation, which helps secure the reliability and accuracy of the questionnaire.

\subsection{Analyzing method}

In accordance with the research goal and characteristics of the research model, factor analysis and regression analysis are chosen for statistical analysis.

\section{Statistic analysis}

The outer reliability is hard to measure due to objective limit. Therefore, we adopt Cronbach's $\alpha$ coefficient to evaluate the inner reliability. As a rule, a value above 0.7 is regarded as acceptable.

Table 1 Results of reliability testing

\begin{tabular}{|c|c|}
\hline Item & Cronbach's $\alpha$ value \\
\hline The level of alliance relationship & 0.8429 \\
\hline Commitment & 0.8230 \\
\hline Trust & 0.7756 \\
\hline Cooperation & 0.7589 \\
\hline
\end{tabular}


(Continued)

\begin{tabular}{lc}
\hline Item & Cronbach's $\alpha$ value \\
\hline Power balancing & 0.7647 \\
Investment in specific assets & 0.8621 \\
Opportunism & 0.8153 \\
Extra returns & 0.7941 \\
Personal relationship & 0.8852 \\
Communication & 0.8214 \\
Government factors & 0.8675 \\
The total reliability of the questionnaire & 0.8662 \\
\hline
\end{tabular}

As shown in Table 1, Cronbach's $\alpha$ coefficients of each variable and the overall questionnaire are all above 0.7 , indicating that there is quite high internal consistency among all variables and items in the questionnaire, thus guarantee a satisfactory reliability. Meanwhile, the main components analysis is adopted to test the construct validity of the questionnaire.

\subsection{Factor analysis}

SPSS software package is used to conduct factor analysis. The results of factor analysis are as follows: The first factor extracted includes commitment, trust, opportunism, specific investment, power balance and personal relationship; the second factor extracted includes cooperation, communication; the third factor extracted includes satisfaction and extra returns; the fourth factor extracted includes administrative factors.

As shown in the above factor analysis results, there lies a close linkage between the factors replaced by factor one: They are all related to commitment and trust. We thus name the first factor "commitment and trust". In a similar vein, we named the rest three factors as "communication and cooperation", "returns" (since both "satisfaction" and "extra returns" refer to the returns channel members gain from the channel alliance relationship) and. "administrative factor", respectively.

\subsection{Multiple liner regression analysis}

From the factor analysis above, we can get the 4 main factors: "commitment and trust", "communication and cooperation", "returns", and "administrative factor". Next, we will use multiple liner regression to analyze these 4 factors. The regression coefficients are shown in Table 2. 
Table 2 Regression coefficients

\begin{tabular}{lcccc}
\hline \multirow{2}{*}{ Model } & \multicolumn{2}{c}{ Unstandardized coefficients } & \multirow{2}{*}{$t$} & \multirow{2}{*}{ Sig. } \\
\cline { 2 - 3 } & $\mathrm{B}$ & Std. Error & & 0.306 \\
\hline 3 (constant) & 5.781 & 4.773 & 1.201 & 0.011 \\
Commitment and trust & 0.370 & 0.002 & 3.004 & 0.000 \\
Cooperation & 0.230 & 0.001 & 6.325 & 0.000 \\
Returns & 0.070 & 0.001 & 6.017 & \\
\hline
\end{tabular}

Table 2 reveals the partial regression coefficients, standardized regression coefficients and corresponding testing values of each model. As a result, if any of the testing values of a variable's corresponding coefficients are blow 0.05, we refuse the null hypothesis. This indicates that they all have positive meaning, and can be added to the regression equation. According to model 3, a multiple liner regression equation can be built:

The level of channel alliance relationship $=5.781+0.37$ commitment and trust +0.23 cooperation +0.007 returns

Correspondingly, administrative factor is eliminated and the previous hypotheses are tested. The results are shown in Table 3.

Table 3 Hypothesis testing results

H1 Channel members' evaluation of on their partner's commitment is posi- supported tively related to the channel alliance relationship.

H2 Channel members' evaluation on their partner's trust is positively related supported to the channel alliance relationship.

H3 Channel members' evaluation on their partner's cooperation is positively supported related to the channel alliance relationship.

H4 Channel members' evaluation of the power balance is positively related to supported the channel alliance relationship.

H5 Channel members' evaluation of the collaborator's investment in specific supported assets is positively related to the channel alliance relationship.

H6 Channel members' evaluation of the collaborator's opportunistic supported propensity is positively related to the channel alliance relationship.

H7 Channel members' evaluation of their own extra returns is positively supported related to the channel alliance relationship.

H8 Channel members' evaluation of the personal relationship with the col- supported laborator is positively related to the channel alliance relationship.

H9 Channel members' evaluation of the communication between the channel supported members is positively related to the channel alliance relationship.

H10 Government factor is positively related to the channel alliance relation- Not ship.

supported

Based on the hypotheses testing results shown in Table 3, we modify our conceptual model as follows (Fig. 2): 


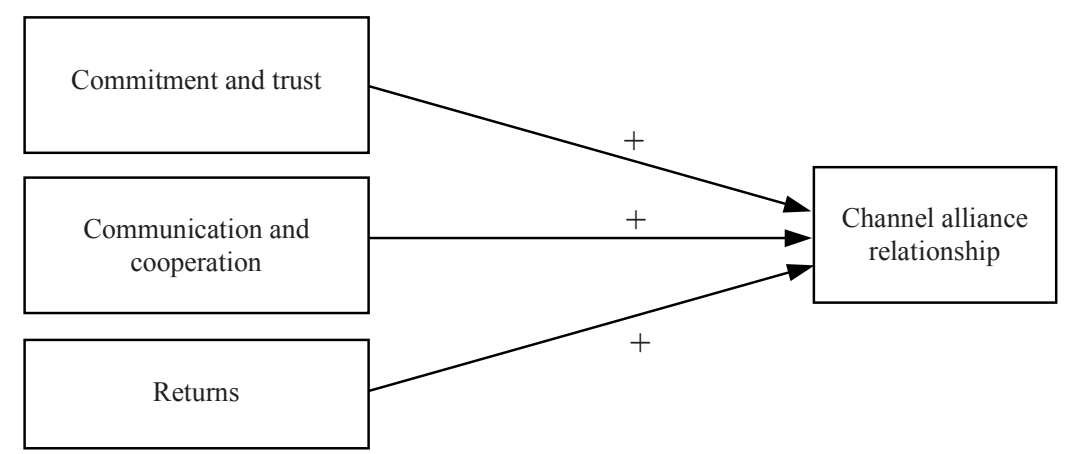

Fig. 2 Modified model of influential factors of channel alliance relationship

\section{Conclusions}

Based on a review of relevant literature on influencing factors, this article empirically identifies 10 important influencing factors of channel alliance relationship. We name the three most important influencing factors as, respectively, "commitment and trust", "communication and cooperation", and "returns". Main conclusions of this paper are listed below:

First, we find that "commitment and trust" is positively related to channel alliance relationship. This finding implies that the establishment, maintenance and development of channel alliance relationship needs channel members' mutual commitment shown by their behaviors. Enhanced trust promotes higher level of commitment in both parties. Commitment and mutual trust complements one another, guaranteeing a sound development of a channel alliance relationship.

Second, this paper verifies that "communication and cooperation" is positively related to channel alliance relationship. This finding implies that in a channel alliance, all members must share common goals and values, under the guidance of which all channel members can cooperate closely with one another. Vague or differentiated goals and values have negative effects on the channel alliance relationship. Another thing worth noting is that lack of cooperation behavior will not eventually lead to failure of alliance relationship in the long run.

Third, the paper also supports that "returns" is positively related to channel alliance relationship. This finding implies that even if the channel members commit to each other, however, in the context of mutual trust, channel alliance may still fail due to lack of efficiency. Thus both suppliers and dealers need 
timely and accurate feedback of the alliance's performance so as to ensure longevity of the channel alliance relationship.

Fourth, the paper finds that "personal relationship" affects channel alliance relationship to a certain degree. This conclusion is deduced from the hypothesis that "commitment" and "trust" is positively related to the channel alliance relationship. It is different from our original assumption and interview results before final survey. During the early phase of our interview, most of the interviewees believed that signed contract and personal relationship have only limited impacts on the channel alliance relationship. They contended that it is necessary to set up clearly defined contracts to guide and regulate commitment, communication, cooperation, profit distributing or relationship establishment, maintenance and development in an alliance. Once contracts are signed, "cooperation" will eventually occur no matter what happened.

With regard to the study on the degree of influence of "personal ties" on channel alliance relationship, out of consideration of statistical process, "personal ties" is included in the first factor "commitment and trust". The later regression equation shows that "personal ties" which is significantly related to the first factor should also have impact on the channel alliance relationship to some degree (correlation coefficient $=0.685$ ).

Fifth, administrative factors such as government policies, rules, etc. are negatively related to channel alliance relationship. Possible explanations are: Administrative factors may work as an important guide for suppliers' channel policies, especially when evaluating and choosing their dealers. However, administrative factors do not function as well when it comes how to communicate and cooperate with the dealers within channels and how to maintain a good channel relationship. These behaviors are self-directed by nature. As long as channel policies do not break relevant government laws and regulations, manufacturers can adjust their relation with dealers to their will and so do the dealers.

Some of the standards and favorable policies made by government, such as new industrial policies both standardizing and encouraging the development of $4 \mathrm{~S}$ shops, also exert some impact on the channel members of the motor industry. For example, the government's encouragement of construction of 4S shops will influence the development direction of existing $4 \mathrm{~S}$ shops as well as the channel policies of automakers. The accelerating expansion of distribution channel may lead to potential conflicts between manufacturers and present dealers. According to our interview results of both manufacturers and dealers, we can see that they adopt a prudential attitude towards the effect $\mathrm{s}$ of the government's policies on motor industrial and their own enterprises. This may be one of the reasons for their negative evaluation of administrative factors. 
Acknowledgements This work is supported by the National Natural Science Foundation of China (No. 70272060).

\section{References}

Anderson E, Weitz B (1992). The use of pledges to build and sustain commitment in distribution channels. Journal of Marketing Research, 29(18): 17-30

Anderson J C, Narus J A (1990). A model of distributor enterprise and manufacturer enterprise working partnerships. Journal of Marketing, 54(1): 42-58

Arias J T (1998). A relationship marketing approach to "Guanxi". European Journal of Marketing, 32(1/2): 145-156

Besanko D, Dranove D, Shanley M (1999). 公司战略经济学 (The Economics of Strategy), 武 亚军(译). 北京: 北京大学出版社

Brouthers K D, Brouthers L E, Wilkinson T J (1995). Strategic alliances: Choose your partners. Long Range Planning, 28(3): 18-25

Davies H, Leung T K P, Luk S T K, Wong Y (1995). The benefits of "Guanxi": The value of relationship in developing Chinese market. Industrial Marketing Management, 24(3): 207-214

Dixon D F, Wilkinson I F (1986). Toward a theory of channel structure, in Bucklin L P and Carman J (eds), Research in Marketing: Distribution Channels and Institutions, Vol. 8. Greenwich, CT: JAI Press

Dwyer S (1994). International strategic alliances: Agency theory perspective. AMA Winter Educators Conference, 5: 175-182

Grewal R, Dharwadkar R (2002). The role of the institutional environment in marketing channels. Journal of Marketing, 66(3): 82-97

Heide J B, Miner A S (1992). The shadow of the future: Effects of anticipated interaction and frequency of contact on buyer-seller cooperation. Academy of Management Journal, 35(2): 265-291

Hutt D M, Mokwa M P, Shapiro S J (1986). The politics of marketing: Analyzing the parallel political marketplace. Journal of Marketing, 50(1): 40-51

Landry J T (1998). Supply chain management: The case for alliances. Harvard Business Review, 76(6): 24-25

Kumar N, Scheer L K, Steenkamp J, Benedict E M (1995). The effects of perceived interdependence on dealer attitudes. Journal of Marketing Research, 32(3): 348-356

Stern L T, EI-Ansary A I, Coughlan A T (2001). 市场营销渠道 (Marketing Channels). 北京: 清 华大学出版社

Lusch R F (1976). Sources of power: Their impact on intrachannel conflict. Journal of Marketing Research, 13(4): 382-390

Mohr J, Nevin J (1990). Communication strategies in marketing channels: A theoretical perspective. Journal of Marketing, 54(10): 36-51

Morgan R M, Hunt S D (1994). The commitment-trust theory of relationship marketing. Journal of Marketing, (3): 20-38

Robicheaux R A, El-ansary A I (1976/77). A general model for understanding channel member behavior. Journal of Retailing, 52(4): 13-32

Vanhonacker W R (2004). Guanxi Networks in China. China Business Review, 31(3): 48-53

Williamson O (1985). The Economics Institutions of Capitalism. New York: Free Press 
白世贞, 王晔丹 (Bai Shizhen, Wang Yedan) (2006). 基于熵的供应链道德风险的内涵研究 (Nature of the moral hazard in the SC based on entropy theory). 物流技术, (2): 49-51

陈洁, 吕薇, 崔鸿 (Chen Jie, Lü Wei and Cui Hong ) (2005). 营销渠道战略联盟形成动因研究 (Research on the changing factors of the formation of marketing channel strategic alliance). 上海管理科学, 27(1): 30-32

韩薇, 席西民 (Han Wei, Xi Youmin) (2001). 关系: 中国商业活动的基本模式探讨 (Is Guanxi a model of China's business?). 西北大学学报(哲学社会科学版), 31(1): 43-47

贺艳春, 周否 (He Chunyan, Zhou Lei) (2004). 论营销渠道战略联盟中相互信任问题 (Mutual trust in the marketing channel strategic alliance). 商业经济与管理, (11): 30-34

李忠鹏 (Li Zhongpeng) (1998). 企业联盟(Enterprises Alliance). 成都: 天地出版社

刘宇伟 (Liu Yuwei) (2002). 营销渠道理论发展及其重心演变 (The theoretic development and the evolvement of marketing channel). 审计与经济研究, (9): 57-59

杨国枢 (Yang Guoshu) (1995). 本土心理学研究 (Study on Local Psychology), 来自组织心理 与行为 (Organizational Psychology and Behavior). 台北：台湾桂冠图书公司

杨慧 (Yang Hui) (2003). 论流通渠道战略联盟实施的几个难点 (On a few difficult points of circulation strategy alliance implement). 江西财经大学学报, (6): 32-36

赵延昇, 董玉芳 (Zhao Yansheng, Dong Yufang) (2001). 建立产销战略联盟一一关于通路创新的 思考 (Establish the produce-sales alliance-Reflects on channel innovation). 乡镇经济, (9): 29-30

庄贵军, 席酉民 (Zhuang Guijun, Xi Youmin) (2004). 中国营销渠道中私人关系对渠道权利使用 的影响 (Impact of personal Guanxi on exercises of power in China's marketing channels). 管理科学学报, (6): 52-62 